\title{
A COMPARATIVE STUDY OF PARTIAL INFERIOR TURBINECTOMY, SUBMUCOSAL DIATHERMY AND INFERIOR TURBINATE BONE RESECTION FOR INFERIOR TURBINATE HYPERTROPHY
}

\author{
N. Gopinathan Pillai1, Binu Babu², Anjana Mary Reynolds 3 , Subadhra $S^{4}$
}

${ }^{1}$ Associate Professor, Department of ENT, Pushpagiri Institute of Medical Sciences and Research Centre, Tiruvalla. ${ }^{2}$ Assistant Professor, Department of ENT, Pushpagiri Institute of Medical Sciences and Research Centre, Tiruvalla. ${ }^{3}$ Assistant Professor, Department of ENT, Pushpagiri Institute of Medical Sciences and Research Centre, Tiruvalla. 4Junior Resident, Department of ENT, Pushpagiri Institute of Medical Sciences and Research Centre, Tiruvalla.

\begin{abstract}
\section{BACKGROUND}

Nasal obstruction is the common symptom encountered by the Otorhinolaryngologist, which disturbs the quality of life of the patient. The anterior end of the inferior turbinate is the narrowest part of the nasal cavity. Hypertrophy of the inferior turbinate cause significant nasal obstruction. Surgery is the treatment of choice in hypertrophic inferior turbinate refractory to medical treatment.(1) There are a variety of surgical procedures for reduction of inferior turbinate hypertrophy, some of these are done targeting soft tissues of the turbinate, whereas others resects bony concha. In this prospective study, a comparison was made among the results of Partial Inferior Turbinectomy (PIT), Submucosal Diathermy (SMD) and Inferior Turbinate Bone Resection (ITBR) in patients with chronic nasal obstruction due to inferior turbinate hypertrophy, not responding to medical treatments. The cases were randomly divided into partial inferior turbinectomy group, submucosal diathermy group and inferior turbinate bone resection group. The study comprised of 114 patients divided into three groups, each of 38 patients. Patients were evaluated postoperatively at $1^{\text {st }}$ week, 1,3 and 6 months and compared. Nasal obstruction, post-operative pain, intra-operative bleeding and crusting were the parameters recorded. The standard 4-point scale was used for bleeding and crusting. Rest of symptoms were assessed subjectively on visual analogue scale ( 0 - 10); statistical analysis was done by student's ' $t$ ' test.
\end{abstract}

\section{MATERIALS AND METHODS}

The present prospective, randomised study was carried out at Pushpagiri Institute of Medical Sciences and Research Centre, Thiruvalla. The study comprised of 114 patients and they were randomly divided into 3 groups, viz. Partial Inferior Turbinectomy group (PIT), Submucosal Diathermy group (SMD) and Inferior Turbinate Bone Resection group (ITBR). There were 50 females and 64 males. Their age ranges from 18 to 50 years, and those associated with septal deviation and polyposis were excluded from this study. All of them were subjected to surgery under general anaesthesia. Patients were evaluated post-operatively at first week, 1,3 and 6 months and compared for nasal obstruction, post-operative pain, intra-operative bleeding and crusting. Rest of the symptoms were assessed subjectively on visual analogue scale $(0-10)$. Statistical analysis was done by student's ' $t$ ' test.

\section{RESULTS}

$100 \%$ improvement of nasal obstruction was recorded in inferior turbinate bone resection group, $92.11 \%$ in partial inferior turbinectomy group and $86.85 \%$ in submucosal diathermy group in our study.

\section{CONCLUSION}

Inferior turbinate bone resection is superior among the three mentioned groups in relieving nasal obstruction and in improvement of quality of life in the present study.

\section{KEYWORDS}

Nasal Obstruction Hypertrophied Turbinate, Partial Inferior Turbinectomy, Submucosal Diathermy, Inferior Turbinate Bone Resection.

HOW TO CITE THIS ARTICLE: Pillai NG, Babu B, Reynolds AM, et al. A comparative study of partial inferior turbinectomy, submucosal diathermy and inferior turbinate bone resection for inferior turbinate hypertrophy. J. Evolution Med. Dent. Sci. 2017;6(23):1886-1889, DOI: 10.14260/Jemds/2017/414

\section{BACKGROUND}

Nasal obstruction is the most common complaint presenting to the otorhinolaryngologist. It disturbs the quality of life and results in large economic burdens.

Financial or Other, Competing Interest: None.

Submission 07-02-2017, Peer Review 04-03-2017,

Acceptance 11-03-2017, Published 20-03-2017.

Corresponding Author:

Dr. N. Gopinathan Pillai,

Associate Professor,

Department of Otorhinolaryngology,

Pushpagiri Institute of Medical Sciences and

Research Centre, Tiruvalla.

E-mail: gopidrent@gmail.com

DOI: $10.14260 /$ jemds $/ 2017 / 414$

\section{(c) $(1) \ominus$}

The most common cause of nasal obstruction is allergy, which leads to hypertrophy of the inferior turbinate. The inferior turbinate is $50-60 \mathrm{~mm}$ long $3-8 \mathrm{~mm}$ wide and 7.5 $\mathrm{mm}$ in height. Hypertrophic rhinitis results in mucosal or submucosal or hypertrophy of the inferior turbinate. Chronic allergic rhinitis is a global problem. Incidence is on the rise due to increasing incidence of air pollution from motor vehicles and industrialisation, poor hygiene, malnutrition, overcrowding, smoking, etc.

It has significant impact on the health related quality of life. Attacks of acute rhinitis and maintenance of this state by the predisposing contributory factors lead to chronic hypertrophic rhinitis. The factors are infections such as sinusitis, chronic tonsillitis, vasomotor rhinitis, chronic nasal mucosal irritation by pollutants, abuse of the therapeutic 
vasoconstrictors, imbalanced diet, vitamin deficiency, thyroid hormone disorders, etc.

\section{Pathology}

External nose is a projecting triangular structure directed downwards and it is divided into two nostrils by a median septum. Each nostril has roof, floor, medial wall and a lateral wall. The bony lateral wall is convoluted by three turbinates. Each turbinate overhangs a meatus. The superior turbinate occupies the posterior third of the lateral wall; the middle turbinate occupies posterior two-thirds and inferior turbinate runs the whole length of the lateral wall. The blood supply of the lateral wall is from Sphenopalatine artery, which is divided into three branches namely inferior turbinate artery, middle turbinate artery and nasopalatine artery.

\section{Nerve Supply}

The main sensory nerve supply comes from maxillary nerve, anterior ethmoidal nerve and infraorbital nerve. Parasympathetic nerve supply from superior salivatory nucleus via vidian nerve and sympathetic nerve supply from superior cervical chain.

\section{Physiology of Nose}

It provides airway for respiration, air conditioning of the inspired air, gives voice resonance, kills the pathogens, filters the suspended particles in the inspired air and olfaction. ${ }^{1}$ All these functions are affected by the nasal obstructions. Hypertrophied turbinate is characterised by chronic hyperaemia of nasal mucosa secondary to inflammatory cells infiltration, fibrosis of submucosa and periosteal thickening of the turbinates. Inferior turbinates are commonly hypertrophied. Epithelium tends to lose its cilia and goblet cells increases; mucous membrane becomes dusky blue in colour. Rhinoscopy shows mulberry appearances. Fibrosis causes lymphatic and venous obstruction. Mucosa fail to shrink with nasal decongestants and corticosteroid drops, so the treatment of choice is surgery. Surgical options are electrocautery of inferior turbinates, ${ }^{2}$ Submucosal Diathermy (SMD), ${ }^{3}$ cryosurgical reduction, ${ }^{4}$ Laser surgery, 5 radiofrequency tissue ablation,6,7 partial inferior turbinectomy (PIT), 8 Inferior Turbinate Bone Resection (ITBR), ${ }^{9}$ etc.

\section{MATERIALS AND METHODS}

In this prospective randomised study was conducted in the Department of Otorhinolaryngology during the period of October 2012 - December 2015 in PIMSRC, Thiruvalla. Total of 114 patients with inferior turbinate hypertrophy were included in this study. These cases were randomly divided into three equal groups. There were 50 female and 64 male patients. Patients below 18 years and above the age of 50 years, and those associated with septal deviation, polyposis were excluded from this study. Evaluation of nasal air flow was done by rhinomanometry, $x$-ray nose and PNS, CT scan of nose and PNS and nasal endoscopy. ${ }^{9-12}$ Patients refractory to medical treatment were subjected to surgical treatment. Surgical treatment is directed towards the mucosa of turbinate, submucosal tissue and turbinate bone. First group is subjected to Partial Inferior Turbinectomy (PIT), second group to Submucosal Diathermy (SMD) and third group to Inferior Turbinate Bone Resection (ITPR).

Patient with persistent nasal obstruction secondary to hypertrophy of inferior turbinates who were refractory to medical treatment with antihistamines, local nasal decongestants, topical steroids were included in the study. All cases were examined thoroughly. The findings were recorded regarding to symptoms on Visual Analogue Scale (VAS) ranging from $0-10 ; 0$ - no symptoms, 10- most severe symptoms. Diagnostic nasal endoscopy was done with $0^{0}$ rigid endoscope. ${ }^{9}$ Computerised tomography of nose and paranasal sinuses was done to exclude other causes of obstruction like deviated nasal septum, nasal polyps, etc.

\section{Partial Inferior Turbinectomy}

After visual inspection, the nose is packed with cottonoids dipped in $4 \%$ xylocaine with adrenaline for five minutes. Then it is removed and the turbinates are injected with $1 \%$ xylocaine with 1:200000 adrenaline. The turbinate is infractured medially with an elevator. With the help of turbinectomy scissors, lower half of the inferior turbinate is resected and nose is packed with antibiotic impregnated gel form and kept for 24 - 28 hours. The patients were put on antibiotics, analgesics, local decongestants for one week postoperatively.

\section{Advantage}

Addressing both soft tissue and mucosa.

\section{Disadvantage}

Bleeding, crusting, rhinitis sicca and atrophic rhinitis, synechiae and recurrence.

\section{Submucous Diathermy}

Popularised by Simpson and Groves (1958).

Unipolar submucosal diathermy needle electrode is carefully inserted into the medial aspect of inferior turbinate staying parallel to bone, to electrocoagulate the tissue. The electrode is slowly withdrawn over a 20 -second period to produce linear submucosal coagulation; this electrode only coagulates the tip.

\section{Advantage \\ Low risk of bleeding.}

\section{Disadvantage}

Crusting and oedema of turbinate, bone death and sequestrum formation and recurrence.

\section{Submucous Resection: Endoscopic Guided}

Incision is made along the inferior surface of the turbinate, mucoperiosteal flap is elevated. Bony concha is resected and the mucoperiosteal flap is repositioned. Removal of the bone and post-operative scarring results in shrinkage and lateralisation of turbinate, thereby reducing the obstruction.

\section{Advantage}

Less bleeding and no recurrence in the present study. Sparing of turbinate mucosa prevents crusting. No atrophic rhinitis, or Rhinitis synechiae. $(10,11,13,14)$ 


\section{Followup}

All cases were evaluated post-operatively after $1^{\text {st }}$ week, $2^{\text {nd }}$ week, one, three and six months. A standard visual analogue scale ranging from 0 - 10 was used to assess subjectively to nasal obstruction, rhinorrhoea and post-operative pain; 0(no symptoms) and 10- (most severe symptoms). ${ }^{10}$

For bleeding and crusting a standard 4-point scale was used.

0- Absent, 1- Mild, 2- Moderate, 3- Severe

\section{Statistical Analysis}

Pre-operative and post-operative data were collected, tabulated. Statistical analysis was done by student's ' $\mathrm{t}$ ' test. A $p$ value of $<0.05$ was considered statistically significant.

\section{RESULTS}

Turbinate reduction were done in 114 patients, age ranges from 18 to 50 years. The maximum incidence was seen in the age group of 29 - 38 years $(45 \%-41 \%)$.

\begin{tabular}{|c|c|c|}
\hline Signs and Symptoms & No. & $\mathbf{\%}$ \\
\hline Nasal obstruction & 114 & 100 \\
\hline Nasal discharge & 40 & 35.08 \\
\hline Post nasal drip & 25 & 21.92 \\
\hline Headache & 30 & 26.3 \\
\hline Obesity & 40 & 35.08 \\
\hline Snoring & 5 & 4.38 \\
\hline Hypertension & 17 & 14.91 \\
\hline Diabetes & 5 & 4.38 \\
\hline Table 1. Signs and Symptoms Pre-operatively \\
\hline
\end{tabular}

\begin{tabular}{|c|c|c|c|c|c|c|c|c|}
\hline \multirow{2}{*}{ Age } & \multicolumn{2}{|c|}{ PIT } & \multicolumn{2}{c|}{ SMD } & \multicolumn{2}{c|}{ ITBR } & \multicolumn{2}{c|}{ Total } \\
\cline { 2 - 9 } & $\mathrm{M}$ & $\mathrm{F}$ & $\mathrm{M}$ & $\mathrm{F}$ & $\mathrm{M}$ & $\mathrm{F}$ & $\mathrm{M}$ & $\mathrm{F}$ \\
\hline $18-28$ yrs. & 4 & 4 & 5 & 6 & 6 & 4 & 15 & 14 \\
\hline $29-38$ yrs. & 11 & 8 & 8 & 8 & 12 & 7 & 31 & 23 \\
\hline $39-50$ yrs. & 6 & 5 & 7 & 4 & 5 & 4 & 18 & 13 \\
\hline \multicolumn{8}{|c|}{ Table 2. Age and Sex Distribution } \\
\hline & 21 & 17 & 20 & 18 & 23 & 15 & 64 & 50 \\
\hline
\end{tabular}

\begin{tabular}{|c|c|c|c|}
\hline & PIT & SMD & ITBR \\
\hline Nasal obstruction & 3 & 5 & 0 \\
\hline Nasal discharge & 1 & 2 & 0 \\
\hline Headache & 2 & 0 & 0 \\
\hline Snoring & 1 & 1 & 0 \\
\hline Synechiae & 0 & 0 & 0 \\
\hline Table 3. Signs and Symptoms Post-operatively \\
in Various Surgeries \\
\hline
\end{tabular}

\section{DISCUSSION}

Inferior turbinate hypertrophy is the commonest cause of nasal obstruction in children and adults.8,15,16,17 Hypertrophy of the inferior turbinate is secondary to mucosal or submucosal or bony hypertrophy. Surgery is the treatment of choice in chronic hypertrophic inferior turbinate refractory to medical treatment.3-8 There are variety of surgical procedures for hypertrophied inferior turbinate reduction. Some to these are targeting the soft tissues, others on the turbinate bone. There is no gold standard method established so far. ${ }^{17}$ An understanding of which part contributes to turbinate enlargement would help the surgeon in deciding which surgical technique to be used. ${ }^{18}$
Submucosal diathermy prevents mucosal damage, surgical trauma. Post-operative pain is much less and theoretically nasal packing is not required. The fibrotic contracture of submucosal tissue of inferior turbinate results in relieving nasal obstruction, nasal discharge and other signs and symptoms. 10

In submucosal diathermy technique, preservation of the inferior turbinate will allow more physiologic airflow distribution within the nasal passages. ${ }^{13}$ The main disadvantages are bleeding and synechia formation.

Nasal obstruction, rhinorrhoea and itching were significantly improved during followup period (6 months) post-operatively.

In ITBR, the mucosal and submucosal tissue are left intact. Only bony concha was removed. Removal of bony concha allows the inferior turbinate to lateralise and shrink.

There was no recurrence of nasal obstruction and other signs and symptoms in present study.

The mean age of 114 patients included in the analysis was 29.63. This study included 50 females and 64 males and each group consists of 38 patients. Neither the difference in ages nor the gender composition among the group was statistically significant. Three patients from PIT and 5 patients from SMD group had nasal obstruction or recurrence after six months. Group ITBR had no nasal obstruction after six months. Complications like synechiae, recurrence were $7.89 \%$ in PIT and in SMD group $13.15 \%$.

\section{Success rate in this study was as follows- \\ SMD $\quad-\quad 86.85 \%$ \\ PIT $\quad-\quad 92.11 \%$ \\ ITBR - $100 \%$}

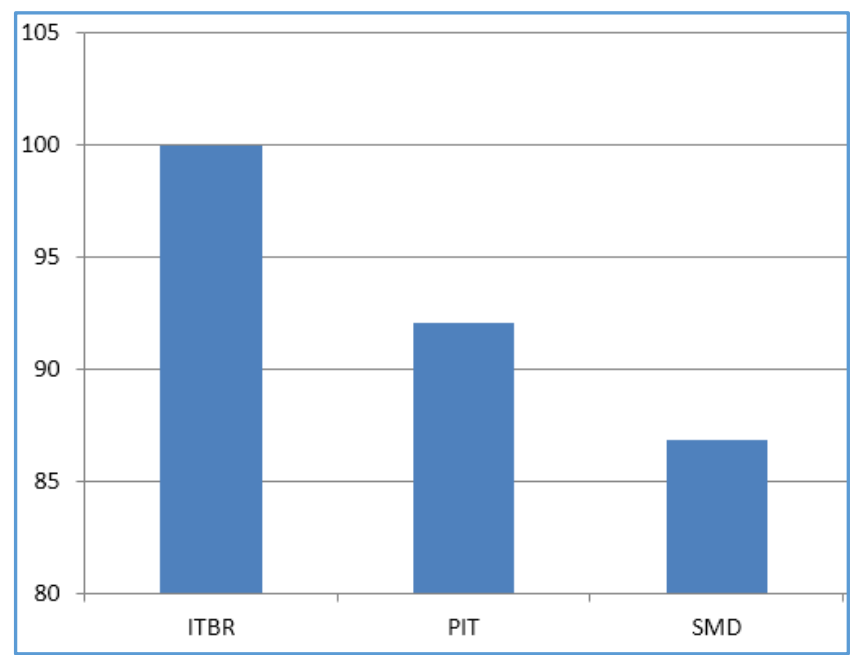

\section{CONCLUSION}

In this study, three surgical methods for inferior turbinate reduction were compared to know the success rate and complications. It was found that ITBR is superior with $0 \%$ recurrence against $7.89 \%$ for partial inferior turbinectomy group and $13.15 \%$ submucosal diathermy group respectively. Chronic nasal obstruction secondary to allergic rhinitis is a global problem and it increases with industrialisation and urbanisation. Chronic rhinitis causes permanent thickening of the turbinates and if it is refractory to medical line of management then the treatment of choice is surgery. 


\section{REFERENCES}

[1] Walsh WE, Kern RC, Friedman M. Sino nasal anatomy, function, evaluation, surgical management. $4^{\text {th }}$ edn. Head and neck surgery -otolaryngology. Lippincott Willian \& Wilkins, Philadelphia 2006:307-13.

[2] Hoover S. The nasal patho-physiology of headaches and migraines. Diagnosis and treatment of the allergy, infection and nasal septal spurs that causes them. Rhinol suppl 1987;2:1-23.

[3] Talaat M, EI-Sabawy E, Baky FA, et al. Submucous diathermy of the inferior turbinates in chronic hypertrophic rhinitis. The journal of Larngology and Otology 1987;101(5):452-60.

[4] Rakover Y, Rosen G. A comparison of partial inferior turbinectomy and cryosurgery for hypertrophic inferior turbinate. J Laryngol otol 1996;110(8):732-5.

[5] Lippert BM, Werner JA. Comparison of carbon dioxide and neodymium: yttrium-aluminum-garnet in surgery of the inferior turbinate. Ann Otol Rhinol Laryngol 1997;106(12):1036-42.

[6] Hytonen ML, Back LJ, Malmivaara AV, et al. Radiofrequency thermal ablation for patient with nasal symptoms: a systematic review of effectiveness and complications. Eur Arch Otorhinolaryngol 2009;266(8):1257-66.

[7] Gupta PJ. Radiofrequency and its uses in ano-rectal surgery. Medicus 2005;6(1):21-4.

[8] Martinez SA, Nissen AJ, Stock CR, et al. Nasal turbinate resection for relief of nasal obstruction. Laryngoscope 1983;93(7):871-5.
[9] Fradis M, Golz A, Danino J, et al. Inferior turbinectomy versus submucosal diathermy for inferior turbinate hypertrophy. Ann Otol Rhinol laryngol 2000;109(11):1040-5.

[10] Whiteaker E. Turbinate reduction Rhinoplasty. In: Granick MS. (eds). Platic surgery, Nose 2006:1-18.

[11] Berger G, Azim MB, Ophir D. The normal inferior turbinate: histomorphometric analysis and clinical implication. Laryngoscope 2003;113(7):1992-8.

[12] Lucente FE. Rhinitis and nasal obstruction. In: Kimmelman CP. (edr). Nasal obstruction: The Otolaryngologic clinics of North Ammerica, W.B. Saunders Company 1989:307-18.

[13] Hol MK, Huizing EH. Treatment of inferior turbinate pathology: a review and critical evaluation of the different techniques. Rhinology 2000;38(4):157-66.

[14] Pollock RA, Rohrich RJ. Inferior turbinate surgery an adjunct to successful treatment of nasal obstruction in 408 patients. Plast Reconstr Surg 1984;74(2):227-36.

[15] Passali D, Lauriello M, Anselmi M, et al. Treatment of hypertrophy of inferior turbinate: long term results in 382 patients randomly assigned to therapy. Ann otorhinolaryngology 1999;108(6):569-75.

[16] Woodhead CJ, Wickham MH, Smelt GJC, et al. Some observations on submucous diathermy. The journal of laryngology and Otology 1989;103(11):1047-9.

[17] Elwany S, Harryson R. Inferior turbinectomy: comparison of four techniques. The journal of Laryngology and Otology 1990;104(3):206-9.

[18] Baig M, Akhtar FP. Management of the hypertrophied inferior turbinate. J Rawal Med Coll 2004;8(2):75-7. 